\title{
Consenso Nacional sobre el estudio de la pareja donante vivo-receptor previo al trasplante renal
}

\author{
National Consensus on the study of the living-donor \\ and recipient prior to kidney transplant
}

\author{
Josefina Alberú-Gómez, * Luis Eduardo Morales-Buenrostro* \\ * Catedrática. Escuela de Medicina. Instituto Tecnológico de Monterrey, Campus Ciudad de México \\ ₹ Responsable del área de Nefrología del Trasplante. Departamento de Nefrología y Metabolismo \\ Mineral. Instituto Nacional de Ciencias Médicas y Nutrición Salvador Zubirán.
}

México cuenta con una larga trayectoria en la práctica de trasplante renal, alternativa considerada la terapia de reemplazo de elección para pacientes con enfermedad renal crónica en etapa terminal en quienes no exista contraindicación absoluta para realizar el procedimiento. La información internacional disponible muestra fehacientemente que el trasplante renal otorga a los pacientes resultados superiores en supervivencia y calidad de vida comparado con cualquier otra modalidad de reemplazo de la función renal, a un costo más bajo comparado con diálisis. México no es la excepción; los análisis efectuados en el Instituto Mexicano del Seguro Social (IMSS) señalan un ahorro de $40 \%$ a cinco años al sustituir diálisis o hemodiálisis por trasplante renal, con un ahorro anual proyectado para 2013 de 511 mdp (Yamamoto-Nagano JA, 2018. Comunicación oral). Recientemente, resultados de un análisis retrospectivo de supervivencia del paciente en procedimientos de reemplazo de la función renal y costos de los mismos, procedente del IMSS y del Instituto de Seguridad y Servicios Sociales de los Trabajadores del Estado (ISSSTE), muestran supervivencias a seis años en diálisis peritoneal, hemodiálisis y trasplante renal de 37.5, 32.6 y $75.8 \%$, respectivamente. El costo de mantenimiento del trasplante renal por paciente por año hacia el sexto año correspondía a $38.8 \%$ del costo en hemodiálisis y a $42.8 \%$ del costo en diálisis peritoneal. (Sánchez-Cedillo A, 2019. Comunicación oral).
Todas las instituciones de Salud Pública nacionales han incorporado progresivamente esta práctica en sus programas de atención y hoy en día existen en el país 159 centros activos públicos y privados que realizan trasplantes renales. Es menester destacar que $82.5 \%$ de los trasplantes renales de donante vivo y fallecido se llevan a cabo en instituciones públicas, instituciones que, además de otorgar el cuidado permanente a los pacientes, están dedicadas a la formación de recursos humanos especializados en esta disciplina en sus aspectos quirúrgico y clínico.

La Sociedad Mexicana de Trasplantes, como institución académica, reúne en su seno a muchos de los partícipes en los programas de trasplante de todo el país. Durante algunos años se había contemplado la necesidad de generar un consenso sobre el estudio del donante renal vivo y el receptor de trasplante renal, por lo que estas reuniones de consenso permiten conocer diversos puntos de vista científicamente fundamentados y posibilita llegar a acuerdos que den como resultado, en este caso, las mejores estrategias de estudio para donantes y receptores. La idea primordial del resultado del consenso tenía como propósito no sacrificar evaluaciones indispensables de donantes y receptores potenciales a fin de garantizar, a la luz del conocimiento actual, los mejores resultados posibles para los pacientes. La convocatoria al consenso fue amplia, incorporando 
especialistas clínicos y quirúrgicos de diversas instituciones públicas y privadas. Los tópicos abordados en el consenso fueron por encargo y los designados tuvieron el compromiso de la revisión pormenorizada del tema para su exposición y ulterior discusión por todo el grupo, con el propósito de incluir al documento final los conceptos acordados. Una nueva revisión del escrito preliminar por todos los integrantes del consenso permitió llevar a cabo observaciones $y$ en su momento modificaciones que permitieran concluir con el documento que ahora tenemos disponible. El material que sustentó la revisión de cada una de las secciones que lo componen fueron las guías publicadas previamente por diversos grupos y sociedades científicas internacionales, artículos de revisión y toda la literatura médica que permitiera sustentar el contenido.

Consideramos indispensable recordar que la práctica de trasplantes en nuestro país debe conducirse de acuerdo con los preceptos de la Declaración de Estam- bul, la cual provee guías claras para las prácticas éticas en esta área. Esta recomendación emana también del Centro Nacional de Trasplantes (CENATRA), institución gubernamental que tiene a su cargo, entre muchas otras funciones, supervisar y garantizar que estas prácticas se conduzcan en estricto apego por lo señalado en el capítulo XIV de la Ley General de Salud.

La Sociedad Mexicana de Trasplantes extiende su más sincero reconocimiento y gratitud a Sanofi-Aventis de México por haber hecho posible la reunión del consenso a través de sus recursos para la Educación Médica Continua. De igual forma, reconoce el esfuerzo y la dedicación de todos los participantes para lograr este resultado. 